\section{Kidney \\ Blood Pressure Research}

Original Paper

\title{
Plasma Lipoprotein(a) Levels and Atherosclerotic Renal Artery Stenosis in Hypertensive Patients
}

\author{
Cristiana Catena GianLuca Colussi Francesca Nait Frine Capobianco \\ Leonardo A. Sechi
}

Hypertension Unit, Internal Medicine, Department of Experimental and Clinical Medical Sciences, University of Udine, Udine, Italy

\section{Key Words}

Lipoprotein(a) • Homocysteine $\cdot$ Prothrombotic state $・$ Renovascular hypertension $\bullet$ Ischemic nephropathy

\begin{abstract}
Background/Aims: The contribution of emergent cardiovascular risk factors to atherosclerotic renal artery stenosis (ARAS) is debated. We investigated the relationship of lipoprotein(a) and prothrombotic factors with ARAS in hypertension. Methods: In 50 hypertensive patients with angiographic evidence of ARAS and 58 hypertensive patients who had comparable cardiovascular risk factor burden but no evidence of renovascular disease, we measured renal function, lipoprotein(a), homocysteine, and hemostatic-fibrinolytic markers. Results: Patients with ARAS were more frequently smokers and had longer duration of hypertension, heavier antihypertensive treatment, and worse renal function than controls. Lipoprotein(a) was higher in patients with ARAS than controls, whereas no differences were found in homocysteine and all hemostatic variables. Multivariate analysis showed that lipoprotein(a) was associated with ARAS independent of other confounders including renal function and history of coronary heart, cerebrovascular, and peripheral artery disease. Conclusion: Lipoprotein(a) might contribute to the development of ARAS and detection of elevated levels of this lipoprotein could raise the suspicion of renovascular disease in patients with high blood pressure.
\end{abstract}




\section{Kidney \\ Blood Pressure Research}

Catena/Colussi/Nait/Capobianco/Sechi: Lp(a) and Renal Artery Stenosis

\section{Introduction}

Atherosclerotic renal artery stenosis (ARAS) has a prevalence comprised from 5 to $10 \%$ in the adult general population [1], prevalence that increases substantially in patients with or without hypertension undergoing angiographic examination of the coronary tree [2] or peripheral arteries [3]. Possible consequences of ARAS are secondary renovascular hypertension $[4,5]$ and renal insufficiency $[4,6]$ caused by ischemic nephropathy. For these reasons, ARAS is now considered a relevant cause of end-stage renal failure and need for dialysis [7]. Although recent studies indicate that revascularization of ARAS does not confer significant benefit over medical therapy in patients with hypertension or chronic kidney disease [8], early diagnosis and treatment of ARAS might modify the natural history of these patients and their cardiovascular and renal outcomes. Unless suspected because of hypertension resistant to treatment or incipient renal failure, early identification of ARAS is difficult to obtain and despite many surrogate tests have been put forward for non-invasive evaluation [9], direct renal angiography remains the gold standard for diagnosis [10].

In addition to hypertension itself $[11,12]$, other traditional cardiovascular risk factors, including aging [12-14], diabetes mellitus [11], smoking [12, 15], and dyslipidemia [12] have been associated to ARAS, although their role was not confirmed in all studies $[16,17]$. Moreover, a variety of conditions that are commonly referred as "emergent" risk factors might be associated with ARAS and contribute to its development [18]. Among these conditions, elevated lipoprotein(a) levels and a prothrombotic state might be of particular interest because both have been shown to have specific relevance for the development of organ damage in hypertensive patients $[19,20]$. Previous studies have suggested a possible contribution to ARAS of plasma fibrinogen [21, 22] and homocysteine [23] levels, whereas the role of lipoprotein(a) remains unclear [21, 24, 25], most likely because none of the studies conducted so far has been specifically designed to investigate its role. This study was designed to investigate whether plasma levels of lipoprotein(a) and hemostatic and fibrinolytic markers are associated with ARAS and can predict its presence in hypertensive patients.

\section{Patients and Methods}

\section{Patients}

Fifty consecutive hypertensive patients (age $67 \pm 10$ yr:; 36 men,14 women) with ARAS detected at renal artery angiography were included in a cross-sectional study. Hypertensive patients were recruited at the Hypertension clinic of our University where they were referred for evaluation. Blood pressure was measured by a validated automated device (Omron M6, OMRON Healthcare Co., Kyoto, Japan) after each patient had been supine for $15 \mathrm{~min}$ and the average of three readings obtained in 5 min was recorded [26]. In all patients, hypertension was diagnosed according to established guidelines when systolic blood pressure was $140 \mathrm{~mm} \mathrm{Hg}$ or more and/or diastolic blood pressure was $90 \mathrm{~mm} \mathrm{Hg}$ or more at least twice on 3 different visits [27]. All the patients were white, lived in the north-east of Italy, and were representative of the hypertensive population in this area [26].

To determine the cause of hypertension, all patients seen at the clinic are routinely screened with clinical and laboratory testing [28] that include analysis of medical records, physical examination, urine analysis, blood biochemistries, duplicate measurements of 24-hour creatinine clearance and urinary sodium excretion, plasma active renin and aldosterone, urinary cortisol and catecholamines, electrocardiogram, echocardiography, and renal ultrasound with duplex Doppler examination of intrarenal vessels [29]. Renal angio-MRI scan or angio-CT scan, adrenal MRI/CT-scan and additional functional tests are performed when indicated $[27,28]$. Renal angiography was performed in all patients in whom increased intrarenal duplex systolic velocity was detected and/or renal artery stenosis was demonstrated either at angio-MRI or angio-CT scan. Angio-MRI or angio-CT scan were done in all hypertensive patients in whom secondary hypertensive disease was suspected due to one or more of the following conditions: severe elevation of 


\section{Kidney \\ Blood Pressure Research}

Kidney Blood Press Res 2015;40:166-175

\begin{tabular}{l|l}
\hline DOI: $10.1159 / 000368492$ & (c) 2015 S. Karger AG, Basel
\end{tabular}

Published online: March 29, 2015

www.karger.com/kbr

Catena/Colussi/Nait/Capobianco/Sechi: Lp(a) and Renal Artery Stenosis

blood pressure with sudden onset or worsening, poor blood pressure response to drug therapy (persistent blood pressure increase with 2 or more drugs), persistent hypokalemia, detection of an abdominal bruit, worsening of renal function (with a 24-hour creatinine clearance of less than $60 \mathrm{ml} / \mathrm{min} / 1.73 \mathrm{~m}^{2}$ of body surface area) either spontaneous or induced by use of angiotensin-converting enzyme inhibitors (ACEi) or angiotensin II-receptor blockers (ARB), difference of more than $1.5 \mathrm{~cm}$ in length between the two kidneys at renal ultrasound [27]. Predefined exclusion criteria were age younger than 25 years or older than 80 years, renal failure with 24-hour creatinine clearance of less than $30 \mathrm{ml} / \mathrm{min} / 1.73 \mathrm{~m}^{2}$, urinary protein excretion greater than $1.0 \mathrm{~g} /$ day, congestive heart failure, recent (less than 6 months) myocardial infarction, unstable angina, or stroke, and presence of concomitant diseases that could affect renal function. Fifty patients with severe ARAS were therefore selected upon angiographic demonstration of renal artery stenosis of $70 \%$ or more in one or more major renal vessels. Patients with lesser degree of renal artery narrowing were excluded. No patient had angiographic characteristics of fibromuscular dysplasia or other types of renal artery disease. Renal and cardiovascular complications of hypertension were assessed by a complete history and physical examination, and laboratory tests that included duplicate measurements of 24-hour creatinine clearance and urinary protein excretion, ECG, echocardiography, and ultrasound examination of aorta, carotid, and iliac arteries. Additional tests included treadmill exercise test, myocardial perfusion scan, coronary angiography, and cerebral CT-scan and were performed when indicated.

Patients with ARAS were compared with 58 hypertensive patients who were consecutively selected during the same time period and using the same criteria as patients with renal artery stenosis, but who had no evidence of renal artery stenosis at angio-MRI or angio-CT scan and/or renal angiography. Patients were classified as smokers if they had smoked for at least 5 years, and up to 1 year before the study. Dyslipidemia was defined by a non-HDL cholesterol of $130 \mathrm{mg} / \mathrm{dl}$ or more and/or as current use of lipid-lowering medication [30]. At the time of the study, patients were allowed to keep their usual unrestricted diet. The study received approval by the local Institutional Review Board and informed consent was obtained from all patients.

\section{Laboratory measurements}

A sample of venous blood was obtained from each patient in the sitting position in the morning after an overnight fast and without venous stasis. Blood was collected into silicone-treated glass tubes, where it was mixed with $10 \%$ of its volume of $0.1 \mathrm{mmol} / \mathrm{l}$ tri-sodium citrate and immediately centrifuged at $1,700 \mathrm{~g}$ for $20 \mathrm{~min}$ at $4{ }^{\circ} \mathrm{C}$. Plasma was separated and frozen at $-80^{\circ} \mathrm{C}$ until being assayed, usually within one month after sampling. Plasma lipids measurement was performed as reported previously [31] and LDL-cholesterol was calculated with the formula of Friedwald. Plasma concentrations of lipoprotein(a) were determined by the Macra ${ }^{\circledR}$ Lp(a) Enzyme Linked Immunosorbent Assay (ELISA) kit (Trinity Biotech PLC, Bray, Ireland) a method that is highly correlated with the reference method used by the WHO for the standardization of the lipoprotein(a) assay [32]. The intra- and inter-assay coefficients of variation for lipoprotein(a) measurements were from $2 \%$ to $7 \%$ and from $6 \%$ to $9 \%$, respectively. Plasma fibrinogen, D-dimer, prothrombin fragment $1+2$, plasminogen-activator inhibitor-1 (PAI-1), tissue plasminogen activator (tPA), and antithrombin III were determined as reported previously [33,34]. Briefly, plasma fibrinogen was measured by a functional assay in an automatic coagulometer autoanalyzer (intra-assay and inter-assay coefficient of variation: 5.1 and $6.8 \%$, respectively); D-dimer was measured immunoenzymatically (intra-assay and inter-assay coefficient of variation: 5.3 and $7.1 \%$, respectively); prothrombin fragment $1+2$ plasma levels were evaluated by ELISA (intra-assay and inter-assay coefficient of variation: 5.5 and $11.2 \%$, respectively); PAI-1 was assayed by enzyme immunoassay (intra-assay and inter-assay coefficient of variation: 4.6 and 6.8\%, respectively); antithrombin III was determined by a functional chromogenic assay (intra-assay and inter-assay coefficient of variation: 7.4 and $8.6 \%$, respectively). All measurements were done in duplicate.

\section{Statistical analysis}

Data are presented as mean \pm SD for variables with normal distribution and as median (interquartile range) for skewed variables. Normally distributed variables were compared with the Student's $t$ test. Variables with skewed distribution were analysed after logarithmic transformation. The Pearson $\chi^{2}$ test was used to compare frequency distributions. Relationships between continuously distributed variables were examined by linear regression analysis and the correlation was expressed by the Pearson's 


\section{Kidney \\ Blood Pressure Research}

Table 1. Clinical characteristics of the study patients

\begin{tabular}{|c|c|c|c|c|}
\hline Characteristics & $\begin{array}{l}\text { All patients } \\
(\mathrm{n}=108)\end{array}$ & $\begin{array}{l}\text { ARAS } \\
(n=50)\end{array}$ & $\begin{array}{l}\text { No ARAS } \\
(n=58)\end{array}$ & $P$ \\
\hline Age, years & $65 \pm 9$ & $67 \pm 10$ & $64 \pm 9$ & 0.064 \\
\hline Males, n (\%) & $70(65)$ & $36 / 14$ & $34 / 24$ & 0.147 \\
\hline $\mathrm{BMI}, \mathrm{kg} / \mathrm{m}^{2}$ & $27.5 \pm 4.7$ & $27.3 \pm 4.6$ & $27.7 \pm 4.9$ & 0.647 \\
\hline Systolic blood pressure, $\mathrm{mm} \mathrm{Hg}$ & $162 \pm 21$ & $162 \pm 23$ & $162 \pm 19$ & 0.981 \\
\hline Diastolic blood pressure, $\mathrm{mm} \mathrm{Hg}$ & $91 \pm 14$ & $89 \pm 13$ & $93 \pm 15$ & 0.185 \\
\hline Duration of hypertension, years & $11[4-20]$ & $12[8-19]$ & $10[5-17]$ & 0.146 \\
\hline Smokers*, n (\%) & $31(29)$ & $17(34)$ & $12(22)$ & 0.120 \\
\hline Diabetes mellitus, n (\%) & $37(34)$ & $19(38)$ & $18(31)$ & 0.447 \\
\hline Dyslipidemia ${ }^{\dagger}, \mathrm{n}(\%)$ & $53(49)$ & $25(50)$ & $28(48)$ & 0.858 \\
\hline Coronary heart disease, $\mathrm{n}(\%)$ & $28(26)$ & $19(38)$ & $9(15)$ & 0.008 \\
\hline Cerebrovascular disease, $\mathrm{n}(\%)$ & $13(12)$ & $7(14)$ & $6(10)$ & 0.561 \\
\hline Peripheral artery disease, $n(\%)$ & $25(23)$ & $21(42)$ & $4(7)$ & $<0.001$ \\
\hline Anti-hypertensive drugs, $\mathrm{n}$ & $2.2 \pm 1.6$ & $2.7 \pm 1.6$ & $1.7 \pm 1.6$ & 0.004 \\
\hline Beta-blockers, n (\%) & $55(51)$ & $30(60)$ & $25(43)$ & 0.185 \\
\hline Diuretics, n (\%) & $49(45)$ & $26(52)$ & $23(40)$ & 0.375 \\
\hline Calcium-channel blockers, n (\%) & $53(49)$ & $27(54)$ & $26(45)$ & 0.608 \\
\hline RAS-blockers, n (\%) & $63(58)$ & $32(64)$ & $31(53)$ & 0.555 \\
\hline Alpha-blockers, n (\%) & $15(14)$ & $9(18)$ & $6(10)$ & 0.335 \\
\hline Lipid-lowering agents, n (\%) & $11(10)$ & $4(8)$ & $7(12)$ & 0.540 \\
\hline \multicolumn{5}{|c|}{$\begin{array}{l}\text { Data are expressed as mean } \pm \text { SD or as median [interquartile range] for variables not normally } \\
\text { distributed. Comparison among patients with or without atherosclerotic renal artery stenosis (ARAS) } \\
\text { was done by the Student } t \text { test or Kruskal-Wallis rank test for variables not normally distributed. BMI, } \\
\text { body mass index; RAS, renin-angiotensin system. } \\
\text { *Patients were classified as smokers if they had smoked for at least } 5 \text { years, and up to } 1 \text { year before } \\
\text { the study; †Dyslipidemia was defined by a non-HDL cholesterol level of } 130 \mathrm{mg} / \mathrm{dl} \text { or more. }\end{array}$} \\
\hline
\end{tabular}

correlation coefficient. Multiple linear regression analysis was performed to identify which variables were independently associated with ARAS and logistic regression analysis to identify which variables predicted the presence of ARAS in hypertensive patients. Two-tailed probability value of less than $5 \%$ was considered to indicate statistical significance. All data analyses were performed using Stata 9.2 (StataCorp LP, TX, USA).

\section{Results}

Among 50 hypertensive patients with angiographic evidence of ARAS, 2 had bilateral stenosis, 2 had unilateral stenosis of the main renal artery and one or more of its branches, and the remaining 46 had unilateral stenosis of the main renal artery. The clinical characteristics of hypertensive patients with or without ARAS are summarized in Table 1. Patients with ARAS used a significantly greater number of anti-hypertensive drugs than patients without ARAS, although the relative frequency of use of different types of these drugs and on-treatment blood pressure levels were comparable in the two groups. Hypertensive patients with ARAS had greater prevalence of coronary heart and peripheral artery disease than patients without ARAS, whereas prevalence of smoking, diabetes, and dyslipidemia was not different.

Table 2 shows the biochemical variables of the study patients. Hypertensive patients with ARAS had higher plasma creatinine and lower 24-hour creatinine clearance than patients without ARAS. Patients with ARAS had also comparable total, HDL, and LDLcholesterol, and triglyceride levels to patients without ARAS, whereas plasma lipoprotein(a) was significantly higher in patients with ARAS, with a $62 \%$ increase in the average plasma concentration. Prevalence of ARAS increased progressively from 31, to 42 and $67 \%$ across plasma lipoprotein(a) tertiles (Figure 1). No significant differences between hypertensive 


\section{Kidney \\ Blood Pressure Research}

Table 2. Biochemical variables of the study patients

\begin{tabular}{|c|c|c|c|c|}
\hline Variable & $\begin{array}{l}\text { All patients } \\
(\mathrm{n}=108)\end{array}$ & $\begin{array}{c}\text { ARAS } \\
(\mathrm{n}=50)\end{array}$ & $\begin{array}{c}\text { No ARAS } \\
(\mathrm{n}=58)\end{array}$ & $\mathrm{P}$ \\
\hline Creatinine, $\mathrm{mg} / \mathrm{dl}$ & $1.15 \pm 0.50$ & $1.27 \pm 0.49$ & $1.05 \pm 0.49$ & 0.026 \\
\hline Creatinine clearance, $\mathrm{ml} / \mathrm{min} / 1.73 \mathrm{~m}^{2}$ & $52 \pm 16$ & $48 \pm 16$ & $57 \pm 15$ & 0.001 \\
\hline Glucose, mg/dl & $103 \pm 31$ & $106 \pm 35$ & $101 \pm 26$ & 0.461 \\
\hline Uric acid, mg/dl & $5.9 \pm 1.5$ & $6.0 \pm 1.4$ & $5.7 \pm 1.6$ & 0.317 \\
\hline Total cholesterol, mg/dl & $194 \pm 47$ & $191 \pm 42$ & $196 \pm 49$ & 0.574 \\
\hline HDL-cholesterol, mg/dl & $55 \pm 15$ & $52 \pm 13$ & $57 \pm 16$ & 0.082 \\
\hline LDL-cholesterol, mg/dl & $116 \pm 43$ & $114 \pm 34$ & $117 \pm 46$ & 0.705 \\
\hline Triglycerides, mg/dl & $113[81-140]$ & 117 [85-155] & $110[80-134]$ & 0.083 \\
\hline Lipoprotein(a), mg/dl & $12.8[5.6-24.5]$ & $16.5[9.5-33.8]$ & $10.2[4.4-16.7]$ & 0.002 \\
\hline C-reactive protein, $\mathrm{mg} / \mathrm{L}$ & $3.0[3.0-6.0]$ & $4.0[3.0-9.4]$ & $3.0[3.0-4.8]$ & 0.200 \\
\hline Homocysteine, $\mu \mathrm{mol} / \mathrm{l}$ & $12.7[9.6-16.7]$ & 13.5 [10.2-18.5] & $12.2[9.5-14.5]$ & 0.175 \\
\hline PT, INR & $1.07 \pm 0.29$ & $1.05 \pm 0.12$ & $1.09 \pm 0.38$ & 0.373 \\
\hline PTT, sec & $29 \pm 5$ & $29 \pm 6$ & $29 \pm 4$ & 0.543 \\
\hline Fibrinogen, mg/dl & 362 [325-430] & 357 [330-424] & 368 [317-432] & 0.629 \\
\hline D-dimer, $\mathrm{ng} / \mathrm{ml}$ & $206[150-347]$ & $263[150-384]$ & $150[150-301]$ & 0.079 \\
\hline $\mathrm{F} 1+2, \mathrm{pmol} / \mathrm{l}$ & $407[180-750]$ & $438[173-750]$ & $380[180-770]$ & 0.641 \\
\hline PAI-1, ng/ml & $11.0[6.3-28.8]$ & $9.4[6.0-25.2]$ & 11.8 [8.6-32.9] & 0.333 \\
\hline $\mathrm{t}-\mathrm{PA}, \mathrm{ng} / \mathrm{ml}$ & $4.17 \pm 2.63$ & $4.58 \pm 2.57$ & $3.75 \pm 2.73$ & 0.470 \\
\hline Antithrombin III, \% & $97 \pm 12$ & $95 \pm 12$ & $99 \pm 13$ & 0.182 \\
\hline
\end{tabular}

Data are expressed as mean \pm SD or as median [interquartile range] for variables not normally distributed. Comparison among patients with or without atherosclerotic renal artery stenosis (ARAS) was done by the Student $t$ test or Kruskal-Wallis rank test for variables not normally distributed. PT, prothrombin time; PTT, partial thromboplastin time; F1+2, prothrombin fragment 1+2; PAI-1, plasminogen-activator inhibitor-1; t-PA, tissue plasminogen activator.

patients with and without ARAS were observed in C-reactive protein, homocysteine, and all hemostatic and fibrinolytic variables under study. Among hypertensive patients with ARAS, lipoprotein(a) levels were not significantly different between those with documented history of coronary heart, cerebrovascular, and peripheral artery disease (22.8 [10.5-39.6] $\mathrm{mg} / \mathrm{dl})$ and those without such history (14.7 [4.4-22.1] mg/dl; $\mathrm{P}=0.088$ ).

Univariate correlation analysis showed that lipoprotein(a) levels were inversely related with creatinine clearance $(\mathrm{r}=$ -0.232, $\mathrm{P}=0.024$ ). In a multiple linear regression analysis, presence of ARAS was included as the dependent variable and de-

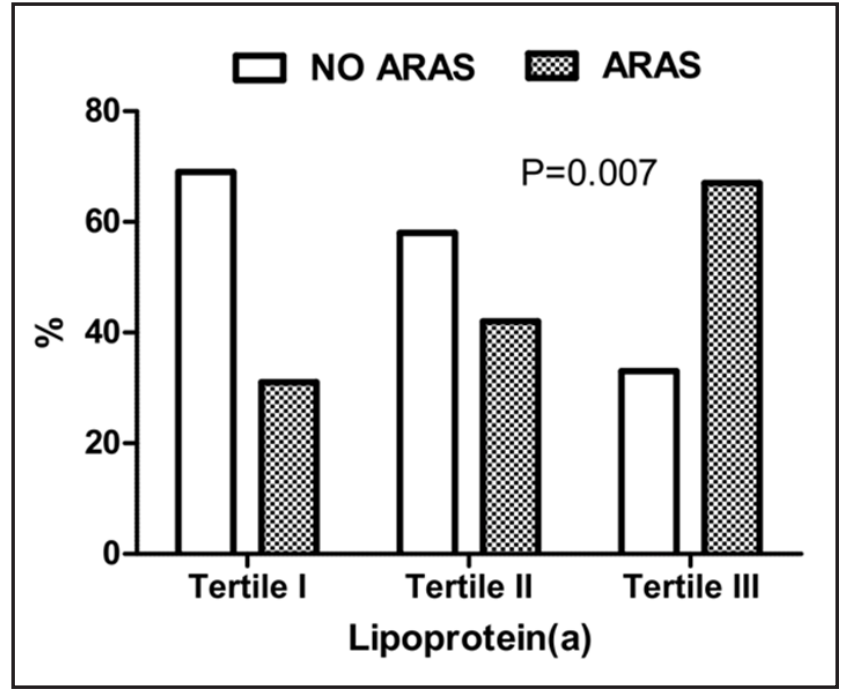

Fig. 1. Bar-graph showing the relative prevalence of hypertensive patients with or without atherosclerotic renal artery stenosis (ARAS) across tertiles of plasma lipoprotein(a) levels.

mographic and anthropometric variables, blood pressure levels, smoking habit, diabetes, creatinine clearance, LDL-cholesterol, coronary heart and peripheral artery disease as independent variables. Analysis showed that peripheral artery disease $(\beta=0.445, \mathrm{P}<0.001)$, 


\section{Kidney Blood Pressure Research}

Table 3. Logistic regression analysis with atherosclerotic renal artery stenosis as the dependent variable

\begin{tabular}{lccc}
\hline Variable & Odds Ratio & $95 \%$ CI & P \\
\hline Age & 0.99 & $0.89-1.09$ & 0.817 \\
Male gender & 0.92 & $0.25-1.27$ & 0.165 \\
Body mass index & 0.94 & $0.83-1.13$ & 0.669 \\
Systolic blood pressure & 1.03 & $0.99-1.08$ & 0.129 \\
Duration of hypertension & 1.08 & $1.01-1.15$ & 0.023 \\
Diabetes & 1.24 & $0.43-1.86$ & 0.517 \\
Smoke & 0.58 & $0.55-3.16$ & 0.768 \\
Coronary heart disease & 2.14 & $0.31-1.51$ & 0.349 \\
Peripheral artery disease & 5.35 & $1.46-3.67$ & $<0.001$ \\
Creatinine clearance & 0.95 & $0.89-1.01$ & 0.057 \\
LDL-cholesterol & 0.98 & $0.96-1.01$ & 0.056 \\
Lipoprotein(a) levels (III vs. I tertile) & 3.70 & $1.28-10.73$ & 0.016 \\
\hline
\end{tabular}

lower creatinine clearance $(\beta=-0.259, P=0.032)$ and higher lipoprotein(a) levels $(\beta=0.233$, $\mathrm{P}=0.046)$ were independently associated with ARAS. Logistic regression analysis that included the same variables as in multivariate regression (Table 3) showed that presence of ARAS was predicted by plasma lipoprotein(a) levels in the highest tertile with an odds ratio of 3.70 versus the lowest lipoprotein $(\mathrm{a})$ tertile $(\mathrm{P}=0.016)$.

\section{Discussion}

A variety of factors could contribute to development and progression of atherosclerotic plaques in major renal arteries leading to renovascular hypertension and/or ischemic nephropathy. In addition to more traditional cardiovascular risk factors, a role might be played by the so called emergent risk factors and the findings of this study demonstrate that elevated levels of lipoprotein(a) are strongly associated with angiographic evidence of ARAS in hypertensive patients. This association is independent of demographic and anthropometric variables, blood pressure levels, smoking, diabetes, and dyslipidemia and, most important, of renal function. Different from lipoprotein(a), no association of hemostatic variables and a prothrombotic state with ARAS has been observed in this study.

Lipoprotein(a) is a heterogeneous lipoprotein whose plasma concentrations varies over a broad range with a distribution that is skewed to low levels [35]. The apolipoprotein(a) gene is the major gene controlling plasma lipoprotein(a) levels [36] and these levels are not modified by either dietary or pharmacologic interventions [37], although a significant decrease in lipoprotein(a) was reported with use of nicotinic acid [38] and studies conducted in hypertensive patients have reported an inverse relationship of lipoprotein(a) levels with alcohol [28] and omega-3 polyunsaturated acid [39] consumption. Longitudinal studies have demonstrated that high plasma lipoprotein(a) is an independent risk factor for atherosclerosis and major cardiovascular events [40,41]. There is also evidence that elevated lipoprotein(a) is strongly and independently associated with presence and severity of hypertension-related cardiac, vascular, and renal damage [42]. Similarly, significant contribution to cardiovascular and renal damage in hypertensive patients has been reported for plasma fibrinogen and D-dimer [43] indicating a role for a prothrombotic state. It must be noticed that in addition to its proatherogenic properties, lipoprotein(a) has prothrombotic effects due to the structural homology with plasminogen. Therefore an interaction between this lipoprotein and the coagulation/fibrinolytic system might have an impact on ARAS and become critical for cardiovascular and renal outcomes of hypertensive patients [19, 20].

Identification of factors that are associated and predispose to ARAS could be important for early detection of disease and may help to prevent the consequences on systemic blood 


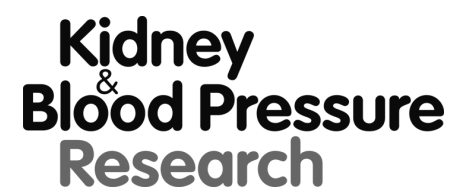

Kidney Blood Press Res 2015;40:166-175

\begin{tabular}{l|l}
\hline DOI: $10.1159 / 000368492$ & C 2015 S. Karger AG, Basel
\end{tabular}

Published online: March 29, 2015

www.karger.com/kbr

Catena/Colussi/Nait/Capobianco/Sechi: Lp(a) and Renal Artery Stenosis

pressure and renal function. The relationship of emergent risk factors for atherosclerosis and ARAS has been investigated in a limited number of previous studies [18], most of which were conducted in small groups of patients. Park et al. [21] detected ARAS (defined by narrowing of arterial lumen by $50 \%$ or more) in 28 of 270 patients who underwent coronary angiography and reported that higher plasma fibrinogen was independent predictor of ARAS with an odds ratio of 1.63 (analyzed by a $100 \mathrm{mg} / \mathrm{dl}$ increment in plasma fibrinogen). Later on, this association was confirmed in hypertensive patients with narrowing of a renal artery by $50 \%$ or more [44]. Furthermore, in 27 patients with ARAS fibrinogen levels were related to an increased rate of restenosis after 1 year of renal artery angioplasty [22]. Levels of homocysteine were reported to be higher in 58 patients with angiographic evidence of ARAS and impaired renal function than in normotensive subjects [23]. However, another study that reported higher homocysteine levels in patients with ARAS than healthy controls could not demonstrate any significant change in these levels 6 months after renal angioplasty [45], therefore questioning the relevance of homocysteine as an independent marker of ARAS. With regard to lipoprotein(a), findings are even more controversial because plasma levels in patients with ARAS have been reported to be higher [24], unchanged [21], or even lower [25] than in subjects without ARAS. A non-significant trend to increased lipoprotein(a) was reported in 26 hypertensive patients with secondary hypertension due to ARAS in comparison to patients with essential hypertension [46]. In addition to the limited statistical power of some of these studies, inconsistencies might be explained by important differences in methodology of selection of patients with ARAS and respective controls, methods used to detect ARAS, criteria used to define critical narrowing of the renal arteries, and inclusion of patients with advanced impairment of renal function. The present study was specifically designed to investigate the relationship of emergent risk factors with ARAS in hypertension and this is why: a) all patients with ARAS had hypertension and were compared with hypertensive subjects with comparable cardiovascular risk who were selected using the same criteria except for evidence of ARAS; b) in all patients ARAS was diagnosed by renal angiography; c) in all patients critical stenosis of renal vessels was defined by stringent criteria (narrowing of $70 \%$ or more); d) patients with advanced renal failure were excluded. With these specific strengths in the study design, results demonstrate that lipoprotein(a) is independently associated and predicts presence of ARAS in hypertensive patients. This observation might have implications for the identification of ARAS in these patients, an issue that will have to be examined in appropriately designed studies.

Some limitations of the study should be discussed. First, the cross-sectional design does not permit to establish evidence of a causal relationship of lipoprotein(a) with ARAS. Second, it is known that circulating levels of lipoprotein(a) are inversely related with glomerular filtration rate in patients with early stages of renal insufficiency [47] and are associated with worse cardiovascular and renal outcomes [31]. Therefore, increased lipoprotein(a) levels in patients with ARAS, as reported in the present study, might result from reduced renal function. As stated above, in this study we excluded patients with 24-hour creatinine clearance of less than $30 \mathrm{ml} / \mathrm{min} / 1.73 \mathrm{~m}^{2}$ and, most important, multivariate regression analysis indicated that the association of lipoprotein(a) with ARAS was independent of renal function. Third, the association of lipoprotein(a) levels with ARAS reported in the study could simply reflect a contribution of this lipoprotein to progression of systemic atherosclerosis. It must be noticed, however, that multivariate logistic analysis showed that this association was independent of other atherosclerosis-related diseases and no significant difference in lipoprotein(a) levels was observed between hypertensive patients with or without history of cardiovascular events. Last, use of a clinic sample might limit the possibility to extend the conclusions of this study to the general population because a bias in the referral of patients to the source of care. 


\section{Kidney \\ Blood Pressure Research}

Catena/Colussi/Nait/Capobianco/Sechi: Lp(a) and Renal Artery Stenosis

\section{Conclusion}

This study demonstrates a strong association of lipoprotein(a) with ARAS in hypertensive patients. This association is independent of renal function and suggests a specific role for this lipoprotein in the pathogenesis of atherosclerosis in major renal vessels. The strength and independence of the association between lipoprotein(a) and ARAS together with the ability of lipoprotein(a) to predict presence of ARAS suggests that measurement of this lipoprotein might be useful in the diagnostic work-up of hypertensive patients to identify those who are at risk of secondary renovascular disease. Appropriately designed and powered studies will be needed to investigate the sensitivity and specificity of lipoprotein(a) levels in detection of ARAS and to test the possible benefits on cardiovascular and renal outcomes of drug treatments or dietary intervention that reduce its plasma levels.

\section{Disclosure Statement}

The authors have no conflict of interest related to the contents of this study to disclose.

\section{Acknowledgments}

This work was supported by a European Cooperation in the field Scientific and Technical Research (COST ADMIRE network, BM1301) grant to C.C. and by a research grant of the Pier Silverio Nassimbeni Foundation to C.C. and L.A.S.

\section{References}

1 Hansen KJ, Edwards MS, Craven TE, Cherr GS, Jackson SA, Appel RG, Burke GL, Dean RH: Prevalence of renovascular disease in the elderly: a population-based study. J Vasc Surg 2002;36:443-451.

2 Cohen MG, Pascua JA, Garcia-Ben M, Rojas-Matas CA, Gabay JM, Berrocal DH, Tan WA, Stouffer GA, Montoya M, Fernandez AD, Halac ME, Grinfeld LR: A simple prediction rule for significant renal artery stenosis in patients undergoing cardiac catheterization. Am Heart J 2005;150:1204-1211.

3 Mui KW, Sleewijk M, van den Hout H, Van Baal J, Navis G, Woittiez AJ: Incidental renal artery stenosis. J Am Soc Nephrol 2006;17:2069-2074.

$4 \quad$ Safian RD, Textor SC: Renal-artery stenosis. N Engl J Med 2001;344:431-442.

5 Working Group on Renovascular Hypertension: Detection, evaluation, and treatment of renovascular hypertension: final report. Arch Int Med 1987;147:820-829.

6 Jacobson HR: Ischemic renal disease: an overlooked clinical entity? Kidney Int 1998;34:729-743.

7 Van Ampting JM, Penne EL, Beek FJ, Koomans HA, Boer WH, Beutler JJ: Prevalence of atherosclerosis renal artery stenosis in patients starting dialysis. Nephrol Dial Transplant 2003;18:1147-1151.

8 Cooper CJ, Murphy TP, Cutlip DE, Jamerson K, Henrich W, Reid DM, Cohen DJ, Matsumoto AH, Steffes M, Jaff MR, Prince MR, Lewis EF, Tuttle KR, Shapiro JI, Rundback JH, Massaro JM, D’Agostino RB, Dworkin LD, for the CORAL Investigators: Stenting and medical therapy fort atherosclerotic renal-artery stenosis. N Engl J Med 2014;370:13-22.

9 Radermacher J, Chavan A, Bleck J, Vitzthum A, Stoess B, Gebel MJ, Galanski M, Koch KM, Haller H: Use of Doppler ultrasonography to predict the outcome of therapy for renal-artery stenosis. N Engl J Med 2001;344:410-417.

10 Erley CM, Bader BD, berger ED, Tuncel N, Winkler S, Tepe G, Risler T, Duda S: Gadolinium-based contrast media compared with iodinate media. Nephrol Dial Transplant 2004;19:2526-2531. 


\section{Kidney \\ Blood Pressure Research}

Catena/Colussi/Nait/Capobianco/Sechi: Lp(a) and Renal Artery Stenosis

11 Caps MT, Perissinotto C, Zierler RE, Polissar NL, Bergelin RO, Tullis MJ, Cantwell-Gab K, Davidson RC, Strandness DE Jr: Prospective study of atherosclerotic disease progression in the renal artery. Circulation 1998;98:2866-2872.

12 Wang Y, Ho DS, Chen WH, Wang YQ, Lam WF, Shen ZJ, Lu CZ, Chui M: Prevalence and predictors of renal artery stenosis in Chinese patients with coronary artery disease. Intern Med J 2003;33:280-285.

13 Hansen KJ, Edwards MS, Craven TE, Cherr GS, Jackson SA, Appel RG, Burke GL, Dean RH: Prevalence of renovascular disease in the elderly: a population-based study. J Vasc Surg 2002;36:443-451.

14 Coen G, Manni M, Giannoni MF, Bianchini G, Calabria S, Mantella D, Pigorini F, Taggi F: Ischemic nephropathy in an elderly nephrologic and hypertensive population. Am J Nephrol 1998;5:1806-1810.

15 Orth SR, Ritz E: The renal risks of smoking: an update. Curr Opin Nephrol Hypertens 2002;11:483-488.

16 Shukla AN, Madan TH, Jayaram AA, Kute VB, Rawal JR, Manjunath AP, Udhreja S: Prevalence and predictors of renal artery stenosis in patients undergoing peripheral and coronary angiography. Int Urol Nephrol 2013;45:1629-1635.

17 Sani SH, Hasanzadeh M, Gholoobi A, Alimi H, allah Esmaily H, Gifani M: Relationship between coronary and renal artery disease and associated risk factors in hypertensive and diabetic patients undergoing coronary angiography. Eurointervention 2008;4:373-377.

18 Paraskevas KI, Hamilton G, Cross JM, Mikhailidis DP: Atherosclerotic renal artery stenosis: association with emerging vascular risk factors. Nephron Clin Pract 2008;108:56-66.

19 Catena C, Novello M, Lapenna R, Baroselli S, Colussi GL, Nadalini E, Favret G, Cavarape A, Soardo G, Sechi LA: New risk factors for atherosclerosis in hypertension: focus on the prothrombotic state and lipoprotein(a). J Hypertens 2005;23:1617-1631.

20 Sechi LA, Catena C, Casaccio D, Zingaro L: Lipoprotein(a), haemostatic variables and cardiovascular damage in hypertensive patients. J Hypertens 2000;18:709-716.

21 Park JS, Park JH, Yang WS, Kim SB, Park SW, Park SJ: Hyperfibrinogenemia as an independent risk factor for atherosclerotic renal artery stenosis. Am J Nephrol 1999;19:649-654.

22 Symonides B, Januszewicz A, Rowinski O, Januszewicz M, Chodakoska J, Berent H, Kuczynska K, Szmigielski C, Malek G, Januszewicz W: Plasma fibrinogen as a risk factor for restenosis after percutaneous transluminal renal angioplasty in patients with atherosclerotic renal artery stenosis. J Cardiovasc Risk 1999;6:269-272.

23 Olivieri O, Friso S, Trabetti E, Girelli D, Pizzolo F, Faccini G, Stranieri C, Pignatti PF, Corrocher R: Homocysteine and atheromatous renal artery stenosis. Clin Exp Med 2001;1:211-218.

24 Zhang Y, Ge J, Qian J, Ye Z: Prevalence and risk factors of atherosclerotic renal artery stenosis in 1.200 Chinese patients undergoing coronary angiography. Nephron Clin Pract 2006;104:185-192.

25 Scoble JE, de Takats D, Ostermann ME, Connolly JO, Scott NR, Beeso JA, Poyser KH, Peters TJ, Sherwood RA: Lipid profiles in patients with atherosclerotic renal artery stenosis. Nephron 1999;83:117-121.

26 Catena C, Zingaro L, Casaccio D, Sechi LA: Abnormalities of coagulation in hypertensive patients with reduced creatinine clearance. Am J Med 2000;109:556-561.

27 Mancia G, De Backer G, Dominczak A, Cifkova R, Fagard R, Germanò G, Grassi G, Heagerty AM, Kjeldsen SE, Laurent S, Narkiewicz K, Ruilope L, Rynkiewicz A, Schmieder RE, Boudier HA, Zanchetti A, Vahanian A, Camm J, De Caterina R, Dean V, Dickstein K, Filippatos G, Funck-Brentano C, Hellemans I, Kristensen SD, McGregor K, Sechtem U, Silber S, Tendera M, Widimsky P, Zamorano JL, Erdine S, Kiowski W, Lindholm LH, Viigimaa M, Adamopoulos S, Agabiti-Rosei E, Ambrosioni E, Bertomeu V, Clement D, Erdine S, Farsang C, Gaita D, Lip G, Mallion JM, Manolis AJ, Nilsson PM, O'Brien E, Ponikowski P, Redon J, Ruschitzka F, Tamargo J, van Zwieten P, Waeber B, Williams B: 2007 ESH-ESC practice guidelines for the management of arterial hypertension. J Hypertens 2007;25:1105-1187.

28 Catena C, Novello M, Dotto L, De Marchi S, Sechi LA: Serum lipoprotein(a) concentrations and alcohol consumption in hypertension: possible relevance for cardiovascular damage. J Hypertens 2003;21:281288.

29 Sechi LA, Di Fabio A, Bazzocchi M, Uzzau A, Catena C: Intrarenal hemodynamics in primary aldosteronism before and after treatment. J Clin Endocrinol Metab 2009;94:1191-1197.

30 Ramjee V, Sperling LS, Jacobson TA: Non-high density lipoprotein cholesterol versus apolipoprotein B in cardiovascular risk stratification: do the math. J Am Coll Cardiol 2011;58:457-463. 


\section{Kidney \\ Blood Pressure Research}

Catena/Colussi/Nait/Capobianco/Sechi: Lp(a) and Renal Artery Stenosis

31 Sechi LA, Zingaro L, Catena C, Perin A, De Marchi S, Bartoli E: Lipoprotein(a) and apolipoprotein(a) isoforms and proteinuria in patients with moderate renal failure. Kidney Int 1999;56:1049-1057.

32 Dati F, Tate JR, Marcovina SM, Steinmetz A: First WHO/IFCC International reference reagent for lipoprotein(a) for immunoassay-Lp(a) SRM 2B. Clin Chem Lab Med 2004;42:670-676.

33 Sechi LA, Zingaro L, Catena C, De Marchi S: Increased fibrinogen levels and hemostatic abnormalities in patients with arteriolar nephrosclerosis: association with cardiovascular events. Thromb Haemost 2000;84:565-570.

34 Sechi LA, Novello M, Colussi GL, Di Fabio A, Chiuch A, Nadalini E, Casanova-Borca A, Uzzau A, Catena C: Relationship of plasma renin with a prothrombotic state in hypertension: relevance for organ damage. Am J Hypertens 2008;21:1347-1353.

35 Hoover-Plow J, Huang M: Lipoprotein(a) metabolism: potential sites for therapeutic targets. Metabolism 2013;62:479-491.

36 Boerwinkle E, Leffert CC, Lin J, Lackner C, Chiesa G, Hobbs HH: Apolipoprotein(a) gene accounts for greater than $90 \%$ of the variation in plasma lipoprotein(a) concentrations. J Clin Invest1992;90:52-60.

37 Kolski B, Tsimikas S: Emerging therapeutic agents to lower lipoprotein(a) levels. Curr Opin Lipidol 2012;23:560-568.

38 Seed M, O'Conner B, Perombelon N, O’Donnell M, Reaveley D, Knight BL: The effects of nicotinic acid and acipimox on lipoprotein(a) concentration and turnover. Atherosclerosis 1993;101:61-68.

39 Colussi GL, Baroselli S, Sechi LA: Omega-3 polyunsaturated fatty acids decrease plasma lipoprotein(a) levels in hypertensive subjects. Clin Nutr 2004;3:1246-1247.

40 O'Donoghue M, Morrow DA, Tsimikas S, Sloan S, Ren AF, Hoffman EB, Desai NP, Solomon SD, Domanski M, Arai K, Chiuve SE, Cannon CP, Sacks FM, Sabatine MS: Lipoprotein(a) for Risk Assessment in Patients with Established Coronary Artery Disease. J Am Coll Cardiol 2014;63:520-527.

41 Nestel PJ, Barnes EH, Tonkin AM, Simes J, Fournier M, White HD, Colquhoun DM, Blankenberg S, Sullivan DR: Plasma Lipoprotein(a) Concentration Predicts Future Coronary and Cardiovascular Events in Patients With Stable Coronary Heart Disease. Arterioscler Thromb Vasc Biol 2013;33:2902-2908.

42 Sechi LA, Kronenberg F, De Carli S, Falleti E, Zingaro L, Catena C, Utermann G, Bartoli E: Association of serum lipoprotein(a) levels and apolipoprotein(a) size polymorphism with target-organ damage in arterial hypertension. JAMA 1997;277:1689-1695.

43 Sechi LA, Zingaro L, Catena C, Casaccio D, De Marchi S: Relationship of fibrinogen levels and hemostatic abnormalities with organ damage in hypertension. Hypertension 2000;36:978-985.

44 Dzielinska Z, Januszewicz A, Demkow M, Makowiecka-Ciesla M, Prejsbiz A, Naruszewicz M, Nowicka G, Kadziela J, Zielinski T, Florczak E, Janas J, Januszewicz M, Ruzyllo W: Cardiovascular risk factors in hypertensive patients with coronary artery disease and coexisting renal artery stenosis. J Hypertens 2007;25:663-670.

45 Minuz P, Patrignani P, Gaino S, Degan M, Menapace L, Tommasoli R, Seta F, Capone ML, Tacconelli S, Palatresi S, Bencini C, Del Vecchio C, Mansueto G, Arosio E, Santonastaso CL, Lechi A, Morganti A, Patrono C: Increased oxidative stress and platelet activation in patients with hypertension and renovascular disease. Circulation 2002;106:2800-2805.

46 Netea RT, Netea MG, Bredie SJ, Demaker PN, Hancu N, Thien T: Lipoprotein(a) concentrations in patients with familial combined hyperlipidemia and hypertension. Neth J Med 1999;55:39-45.

47 Sechi LA, Zingaro L, De Carli S, Sechi G, Catena C, Falleti E, Dell'Anna E, Bartoli E: Increased serum lipoprotein(a) levels in patients with early renal failure. Ann Intern Med 1998;129:457-461. 